\title{
Screening for Cervical Cancer - Uptake and Associated Factors in a Representative Sample in the City of Patras, West-Greece
}

\author{
Eleni Jelastopulu ${ }^{1, *}$, Pania Karnaki ${ }^{2}$, Christos Bartsokas ${ }^{1}$, Panagiotis Plotas ${ }^{1}$, Aris Sissouras ${ }^{3}$ \\ ${ }^{1}$ Public Health Department, Medical School, University of Patras, Patras, Greece \\ ${ }^{2}$ Institute of Preventive Medicine, Environmental and Occupational Health, Athens, Greece \\ ${ }^{3}$ Department of Operational Research and Management, University of Patras, Patras, Greece \\ *Corresponding Author: jelasto@upatras.gr
}

Copyright (C) 2013 Horizon Research Publishing All rights reserved.

\begin{abstract}
The aim of this study is to provide a profile of cervical cancer screening practices among the women in Patras and to assess factors associated with cervical cancer screening uptake. Data from a representative sample of 873 women were analyzed. $67.2 \%$ had at least one Pap test in their life, with $54.4 \%$ having been tested in the previous three years. Women aged 35-44 and 45-54 years were more likely to have had a recent Pap test $(\mathrm{OR}>3)$ as well as married/partnered women $(\mathrm{OR}=2.4)$. Unemployed women and women with the lowest educational level were less likely to have had a recent Pap test. Compared to women with a monthly household income of $<500 €$, those with higher income were more likely to have had a Pap test.

The prevalence of Pap testing in Patras is very low. Our findings support the necessity of implementation of national screening programs or targeted screening interventions mainly in the identified under-screened population subgroups, i.e. women with socioeconomic disadvantages.
\end{abstract}

Keywords Cervical cancer, Greece, Pap-test, screening

\section{Introduction}

The Health profile of the city of Patras was conducted in 2006 with the aim of collecting information about the current socioeconomic and demographical situation of its citizens, their living conditions and health status as well as health related behaviors including cervical cancer screening. Cervical cancer is the third most common cancer in women worldwide. It accounts for almost $9 \%$ of the total number of new cancer cases diagnosed and $8 \%$ of the total number of cancer deaths among females [1]. More than $85 \%$ of deaths due to cervical cancer occur in developing countries. This disproportionately high burden of cervical cancer cases in developing countries and elsewhere among medically underserved populations is largely due to insufficient screening that allows the detection of precancerous lesions or early stage cervical cancer [2].

In 2008, 31,038 cervical cancer cases were diagnosed in the EU-27 member states (MS) and 13,430 died from the disease in the same year [1]. Although the burden of cervical cancer varies among these countries the most profound difference is observed between the old and the new MS which to a large extent have yet to implement population based organized screening programs for cervical cancer $[3,4]$.

Organized population based cervical cancer screening every 3-5 years that applies quality assurance measures can reduce the incidence of cervical cancer up to $80 \%$. In countries that have established such programs - which tend to be part of the developed world - cervical cancer incidence has showed a marked decrease $[5,6]$.

The EU Council recommends that population-based cervical cancer screening programs that apply quality assurance at all levels as outlined in the European guidelines are implemented in all MS [7].

Based on these recommendations most MS have implemented population based organized cervical cancer screening programs either nationally or regionally. Greece is among the few European countries that have yet to establish national organized screening for cervical cancer [3]. Screening in Greece is opportunistic and conducted primarily through public and university hospitals, some primary health care centers, and social insurance health services. A number of large metropolitan gynecological hospitals - for example in Athens - have very well organized programs but reliable data on the percentage of women covered are not available. National Health Service (NHS) screening services generally have long waiting lists something that discourages women from having frequent tests [8-10]. Private gynecologists also perform Pap tests in their private practices although these are not free of cost. There are no reliable data on the percentage of women who perform Pap tests privately. 
Two regional organized cancer screening programs exist in Greece in Ormylia, Halkidiki in Northern Greece and in the prefectures of Messinia and Ilia in Southern Greece. Although successful since their implementation in 1991 these programs cover a small percentage of the overall population [8-10].

There are plans to establish a national organized population based screening program for cervical cancer as mentioned in the National Action Plan for Cancer which has been in effect since 2008. Given the current financial crisis there is no timeline for the implementation of these plans [11].

Available data indicate a general downward trend in cervical cancer mortality rates in Greece as in all old EU member states compared to the new MS $[3,12]$.

According to the WHO/ICO Information Centre on HPV and Cervical Cancer [13], in Greece in 2008 the crude mortality rate for cervical cancer was 2.8 per 100.00 women while the age-standardized mortality rate was 1.5 per 100 000 women.

The aim of this paper is to provide a profile of cervical cancer screening practices among the women in Patras and discuss the implications for the establishment of an organized population based screening program.

\section{Materials and Methods}

\subsection{Study Design, Data Collection and Study Population}

The data were collected between June and July 2006 through a structured survey questionnaire. Detailed questionnaires were distributed to a representative sample of 873 women aged 18 to 74 years old and residents of Patras, selected by stratified sampling based on the census data of Patras.

The outcome variable of interest for this analysis was the proportion of women who have ever had a Pap-test and the proportion of women who had had a Pap-test within the last 3 years before the study. Independent variables included demographic and socioeconomic characteristics, such as age in years, marital status, educational level, household income, house ownership, health care coverage and occupational status. Secondary characteristics included body mass index (BMI categorized as underweight [18.5-19.9 kg/m2], within acceptable limits [20-24.9 kg/m2], overweight [25-29.9 kg/m2], obese [ $>=30 \mathrm{~kg} / \mathrm{m} 2]$ ), tobacco exposure (expressed in pack-years and defined as 1 pack-year corresponding to twenty cigarettes smoked every day for one year) and alcohol consumption.

\subsection{Statistical Analysis}

The statistical analysis was conducted by using SPSS software program version 17.0. The age-weighted prevalence estimates of "Ever having had a Pap test" and "Having had Pap test in the past 3 years" were calculated.
The relationship between cervical cancer screening behavior and demographic, clinical, and lifestyle factors was assessed by using Pearson's chi square $(\chi)$ in SPSS cross tabulation. Chi square $(\chi)$ results were considered statistically significant at $\mathrm{p}<=0.05$. To further assess these relationships multiple (multivariate) logistic regression models were applied. The prevalence odds ratios and their $95 \%$ confidence intervals $(\mathrm{CI})$ were estimated to determine the magnitude of the association between the specific factors and cervical cancer screening behavior. The variables significantly associated with cervical cancer screening $(\mathrm{p}<0.05)$, odds ratios (OR) and 95\% CI were calculated using logistic regression analysis. All data were weighted by respondent's age.

\section{Results}

The main demographic and socioeconomic characteristics of the study population are presented in table 1. From the 873 women, $67.2 \%$ had ever had a Pap test and $54.4 \%$ had been tested in the previous three years (Table 1).

Table 1. Basic demographic and socioeconomic characteristics of the study population $(n=873)$

\begin{tabular}{|c|c|c|}
\hline Characteristics & $\begin{array}{c}\text { Number } \\
\text { (n) }\end{array}$ & $\begin{array}{c}\text { Percentage } \\
(\%)\end{array}$ \\
\hline \multicolumn{3}{|l|}{ Ever had Pap-test } \\
\hline Yes & 587 & 67.2 \\
\hline No & 286 & 32.8 \\
\hline \multicolumn{3}{|l|}{ Time since last Pap-test } \\
\hline$<3$ years ago & 475 & 54.4 \\
\hline$>3$ years ago & 99 & 11.3 \\
\hline Don't remember & 13 & 1.5 \\
\hline Never & 286 & 32.8 \\
\hline \multicolumn{3}{|l|}{ Respondent's age } \\
\hline $18-24$ & 126 & 14.4 \\
\hline $25-34$ & 180 & 20.6 \\
\hline $35-44$ & 168 & 19.2 \\
\hline $45-54$ & 167 & 19.1 \\
\hline $55-64$ & 133 & 15.2 \\
\hline $65-74$ & 99 & 11.3 \\
\hline \multicolumn{3}{|l|}{ Marital status } \\
\hline Single & 216 & 24.7 \\
\hline Married/Partnered & 547 & 62.7 \\
\hline Formerly married & 110 & 12.6 \\
\hline \multicolumn{3}{|l|}{ BMI } \\
\hline Underweight & 40 & 4.7 \\
\hline Normal & 460 & 53.7 \\
\hline Overweight & 239 & 27.9 \\
\hline Obese & 118 & 13.7 \\
\hline \multicolumn{3}{|l|}{ Educational status } \\
\hline Primary $(<6$ years $)$ & 41 & 4.7 \\
\hline Lower secondary (6-9 years) & 319 & 36.8 \\
\hline Higher secondary (9-12 years) & 348 & 40.2 \\
\hline Tertiary $(>12$ years $)$ & 159 & 18.3 \\
\hline
\end{tabular}




\begin{tabular}{|c|c|c|}
\hline $\begin{array}{l}\text { Occupational status } \\
\text { Employed } \\
\text { Unemployed }\end{array}$ & $\begin{array}{l}263 \\
609\end{array}$ & $\begin{array}{l}30.2 \\
69.8\end{array}$ \\
\hline $\begin{array}{l}\text { Home ownership } \\
\text { Yes } \\
\text { No }\end{array}$ & $\begin{array}{l}672 \\
201\end{array}$ & $\begin{array}{l}77.0 \\
23.0\end{array}$ \\
\hline $\begin{array}{c}\text { Household income }(€) \\
<500 \\
500 \leq 1000 \\
1000 \leq 1500 \\
1500 \leq 2000 \\
2000 \leq 2500 \\
2500 \leq 3000 \\
>3000 \\
\text { No response }\end{array}$ & $\begin{array}{c}58 \\
220 \\
199 \\
151 \\
98 \\
51 \\
38 \\
58\end{array}$ & $\begin{array}{c}6.6 \\
25.2 \\
22.8 \\
17.3 \\
11.2 \\
5.8 \\
4.5 \\
6.6\end{array}$ \\
\hline $\begin{array}{c}\text { Insured } \\
\text { Yes } \\
\text { No } \\
\end{array}$ & $\begin{array}{r}829 \\
44 \\
\end{array}$ & $\begin{array}{c}95.0 \\
5.0 \\
\end{array}$ \\
\hline $\begin{array}{c}\text { Nationality } \\
\text { Greek } \\
\text { Other }\end{array}$ & $\begin{array}{c}838 \\
35\end{array}$ & $\begin{array}{c}96.0 \\
4.0\end{array}$ \\
\hline $\begin{array}{c}\text { Presence of health problems } \\
\text { Yes } \\
\text { No }\end{array}$ & $\begin{array}{l}471 \\
402\end{array}$ & $\begin{array}{l}54.0 \\
46.0\end{array}$ \\
\hline $\begin{array}{c}\text { Alcohol consumption } \\
\text { Yes } \\
\text { No }\end{array}$ & $\begin{array}{l}542 \\
331\end{array}$ & $\begin{array}{l}62.1 \\
37.9\end{array}$ \\
\hline $\begin{array}{c}\text { Alcohol frequency } \\
\text { Never/Rare } \\
>1 \text { time/week } \\
\end{array}$ & $\begin{array}{l}264 \\
278\end{array}$ & $\begin{array}{l}48.7 \\
51.3\end{array}$ \\
\hline $\begin{array}{c}\text { Heavy alcohol consumption } \\
\text { ("more than } 4 \text { glasses") } \\
\text { Never/rare } \\
>1 \text { time/week }\end{array}$ & $\begin{array}{l}361 \\
181\end{array}$ & $\begin{array}{l}66.6 \\
33.4\end{array}$ \\
\hline $\begin{array}{l}\text { Smoking habits } \\
\text { Non Smoker } \\
\text { Former Smoker } \\
<1 \text { pack-years } \\
1 \text { to } 5 \text { pack-years } \\
>5 \text { pack-years }\end{array}$ & $\begin{array}{c}442 \\
61 \\
112 \\
206 \\
46\end{array}$ & $\begin{array}{c}50.6 \\
6.7 \\
12.8 \\
13.6 \\
5.3\end{array}$ \\
\hline
\end{tabular}

Women were more likely to have had a recent Pap test if they were aged $35-44(\mathrm{OR}=5.0$ vs. age $18-24,95 \% \mathrm{CI}$ $2.2-11.5)$ or $45-54(\mathrm{OR}=3.0$ vs. age $18-24,95 \%$ CI $1.4-6.7)$ and if they were married/partnered (OR=2.4 vs. single, $95 \%$ CI 1.4-4.1) (Table 2, Table 3). Women with no education or belonging to the lowest educational level were less likely to have had a recent Pap test $(\mathrm{OR}=0.2$ vs. $>12$ years education, $95 \%$ CI $0.1-0.5)$ as well as unemployed women ( $\mathrm{OR}=0.5$ vs. employed, 95\% CI 0.3-0.7). Compared to women with a monthly household income of less than $<500 €$, those with higher incomes were more likely to have had a Pap test. There was no statistically significant difference between screening behavior and BMI, health care coverage and house ownership.

In cross tabulation analysis "ever having had a Pap test" was significantly associated $(\mathrm{p}<0.05)$ with age, marital status, educational status, household income, occupational status, nationality, presence of health problems, alcohol frequency, heavy alcohol consumption, house ownership and smoking. Lower rates of Pap screening were observed in younger, single women, women with lower household income, unemployed and other nationalities except Greek. Moreover women, who had more than five smoking pack-year history, had higher rates of Pap test screening. In addition, higher rates of screening in the last 3 years were found in women who had university education and with a household income of more than 2,000€ per month. Pap screening test was not associated with BMI, and health care coverage.

In the multivariate logistic regression models, the response variables were "Ever having had a Pap test" and "Having had Pap test in the past 3 years". Our estimates show that older age groups had higher screening rates than younger women by 2 to 5 times (Table 2, Table 3 ). Furthermore married or partnered women were screened 2 times more than single women. Occupational status and presence of health problems were negatively associated with having had a Pap test while household income was positively associated (Table 3 ).

Table 2. Screening history (ever cervical smear, up to 3 years cervical smear) by age group of respondent ( $\mathrm{n}=873$ )

\begin{tabular}{|c|c|cc|cc|}
\hline Age group (years) & $\begin{array}{c}\text { Total number } \\
\text { in sample }\end{array}$ & $\begin{array}{c}\text { Ever Pap test } \\
\%(95 \% \mathrm{CI})\end{array}$ & $\mathrm{N}$ & \multicolumn{2}{|c|}{$\begin{array}{c}\text { Up to 3 years Pap test } \\
\%(95 \% \mathrm{CI})\end{array}$} \\
\hline $18-24$ & 126 & $29.4(21.4-34.3)$ & 37 & $28.6(20.7-36.5)$ & $\mathrm{N}$ \\
$25-34$ & 180 & $66.1(59.2-73.0)$ & 119 & $58.3(51.1-65.5)$ & 105 \\
$35-44$ & 168 & $85.1(79.7-90.5)$ & 143 & $73.2(66.5-79.9)$ & 123 \\
$45-54$ & 167 & $81.4(75.5-87.3)$ & 136 & $69.5(62.5-76.5)$ & 116 \\
$55-64$ & 133 & $76.7(69.5-83.9)$ & 102 & $54.9(46.4-63.4)$ & 73 \\
$65-74$ & 99 & $50.5(40.6-60.4)$ & 50 & $22.2(14.0-30.4)$ & 22 \\
\hline Total & 873 & $67.2(64.1-70.4)$ & 587 & $54.4(51.1-57.7)$ & 475 \\
\hline
\end{tabular}


10 Screening for Cervical Cancer - Uptake and Associated Factors in a Representative Sample in the City of Patras, West-Greece

Table 3. Odds ratios of screening history (ever Pap test, up to 3 years Pap test) by sociodemographic characteristics $(\mathrm{n}=873)$

\begin{tabular}{|c|c|c|c|c|c|c|}
\hline & \multicolumn{3}{|c|}{ Ever vs Never Pap test } & \multicolumn{3}{|c|}{ Up to 3 years vs Never Pap test } \\
\hline & $\%$ & OR $(95 \% \mathrm{CI})$ & p-value & $\%$ & OR $(95 \% \mathrm{CI})$ & $\mathrm{p}$-value \\
\hline \multicolumn{7}{|l|}{ Age } \\
\hline $18-24$ & 29.4 & 1.0 & & 28.6 & 1.0 & \\
\hline $25-34$ & 66.1 & $2.13(1.14-4)$ & .018 & 58.3 & $1.99(1.04-3.79)$ & .036 \\
\hline $35-44$ & 85.1 & $6.85(3.15-14.92)$ & .000 & 73.2 & $5.59(2.50-12.50)$ & .000 \\
\hline $45-54$ & 81.4 & $5.29(2.52-11.11)$ & .000 & 69.5 & $4.57(2.10-9.90)$ & .000 \\
\hline $55-64$ & 76.7 & $3.21(1.52-6.60)$ & .002 & 54.9 & $2.40(1.08-5.32)$ & .032 \\
\hline $65-74$ & 50.5 & $1.63(.76-3.52)$ & .212 & 22.2 & $.62(.27-1.44)$ & .264 \\
\hline \multicolumn{7}{|l|}{ Marital status } \\
\hline Single & 44.7 & 1.0 & & 38.8 & 1.0 & \\
\hline Married/partnered & 77.2 & $2(1.25-3.19)$ & .004 & 59.9 & $2.02(1.21-3.38)$ & .007 \\
\hline Formerly married & 63.1 & $1.29(.74-2.23)$ & .369 & 42.6 & $1.43(.78-2.62)$ & .254 \\
\hline \multicolumn{7}{|l|}{ Educational status } \\
\hline Primary ( $<6$ years) & 41.1 & 1.0 & & 16.9 & 1.0 & \\
\hline Lower secondary (6-9 years) & 70.1 & $2.79(1.74-4.64)$ & .000 & 49.5 & $3.42(1.86-8.33)$ & .000 \\
\hline Higher secondary (9-12 years) & 73.7 & $3.98(2.78-6.99)$ & .000 & 58.9 & $4.54(2.31-9.10)$ & .000 \\
\hline Tertiary $(>12$ years $)$ & 80.3 & $3.50(1.89-6.45)$ & .000 & 75.2 & $4.98(2.42-10.31)$ & .000 \\
\hline \multicolumn{7}{|l|}{ Occupational status } \\
\hline Employed & 81.5 & 1.0 & & 72.0 & 1.0 & \\
\hline Unemployed & 66.7 & $.43(.30-.62)$ & .000 & 47.7 & $.41(.28-.58)$ & .000 \\
\hline \multicolumn{7}{|l|}{ Household income } \\
\hline$<500 €$ & 46.8 & 1.0 & & 25.9 & 1.0 & \\
\hline $500 \leq 1000$ & 59.8 & $3.39(2.07-5.52)$ & .000 & 39.8 & $1.92(1.11-3.44)$ & .020 \\
\hline $1000 \leq 1500$ & 76.6 & $3.54(2.11-5.95)$ & .000 & 58.2 & $2.29(1.29-4.10)$ & .005 \\
\hline $1500 \leq 2000$ & 76.5 & $2.95(1.69-5.13)$ & .000 & 65.0 & $2.21(1.20-4.08)$ & .011 \\
\hline $2000 \leq 2500$ & 82.6 & $4.13(2.20-7.81)$ & .000 & 67.2 & $2.99(1.53-5.88)$ & .001 \\
\hline $2500 \leq 3000$ & 84.0 & $4.20(2.06-8.62)$ & .000 & 75.0 & $3.30(1.53-7.09)$ & .002 \\
\hline$>3000 €$ & 80.4 & $4.03(1.75-9.35)$ & .001 & 78.6 & $4.07(1.68-6.22)$ & .002 \\
\hline \multicolumn{7}{|c|}{ Presence of health problems } \\
\hline Yes & 71.1 & 1.0 & & 53.0 & 1.0 & \\
\hline No & 69.5 & $.66(.48-.90)$ & .009 & 56.0 & $.68(.50-.93)$ & .015 \\
\hline \multicolumn{7}{|l|}{ Nationality } \\
\hline Greek & 71.1 & 1.0 & & 54.2 & 1.0 & \\
\hline Other & 58.1 & $.11(.06-.22)$ & .000 & 47.3 & $.11(.05-.22)$ & .000 \\
\hline \multicolumn{7}{|l|}{ Alcohol frequency } \\
\hline Never/rare & 72.3 & 1.0 & & 53.6 & 1.0 & \\
\hline$>1$ times/week & 68.1 & $.79(.61-1.02)$ & .072 & 55.9 & $.81(.61-1.04)$ & .136 \\
\hline \multicolumn{7}{|l|}{ Smoking habits } \\
\hline Non Smoker & 65.3 & 1.0 & & 49.2 & 1.0 & \\
\hline Former Smoker & 79.4 & $1.39(.85-2.89)$ & .189 & 62.4 & $1.43(.84-2.45)$ & .190 \\
\hline$<1$ pack-year & 59.6 & $.58(.37-.90)$ & .015 & 48.0 & $.52(.32-.82)$ & .005 \\
\hline $1-5$ pack-years & 81.8 & $1.19(.84-1.70)$ & .321 & 65.1 & $1.02(.71-1.46)$ & .437 \\
\hline$>5$ pack-years & 78.9 & $2.99(1.55-5.78)$ & .001 & 53.4 & & .080 \\
\hline \multicolumn{7}{|l|}{ Home ownership } \\
\hline Yes & 71.9 & 1.0 & & 55.3 & 1.0 & \\
\hline No & 64.0 & $1.31(.92-1.87)$ & .132 & 48.1 & $1.12(.28-.58)$ & .575 \\
\hline
\end{tabular}




\section{Discussion}

The estimated prevalence rates of screening for cervical cancer are relatively low among women living in Patras as one in two women had not been tested in the previous three years. Screening rates in the EU differ between Member States (MS) with the highest screening achieved in the United Kingdom, Norway and Sweden where rates reach as high as $80 \%$ while the lowest ones are observed in Hungary and the Slovak Republic.

There are no reliable data concerning screening rates in Greece due to the large number of opportunistic testing and the lack of an organized population based approach. The systematic examination of factors associated with cervical cancer screening among women in the city of Patras has led to a deeper understanding of the characteristics of under screened women in Patras. Consequently health promotion actions can be targeted to increase the number of women from specific socioeconomic categories who screen.

The present study shows that younger (18-24) and older (65-74) Greek women reported lower rates of cervical cancer screening than women aged 35-54. Of interest is the low prevalence of screening among women aged 18-24 years in Greece $(29.4 \%)$, possibly related to the fact that screening in Greece is recommended for women between 25 to 65 years $[14,15]$. In addition, women with household income of at least $2,000 €$, were 3 to 4 times more likely to have been screened compared to those with lower household income. Household income has been found in multiple studies to be positively correlated with screening uptake, possibly due to greater financial freedom as a result of higher income [16-24]. Although the Greek NHS offers free cervical cancer screening, long waiting lists can discourage women - especially women of lower socioeconomic status - to access them. Another reason for this is that women of higher income have a better understanding of the benefits of screening in detecting precancerous lesions [25].

Low income impacts health seeking behaviors such as cervical screening in many ways other than difficulties in health services utilization. Women from low income backgrounds often are not able to utilize public services due to long working hours or inability to access public services due to long distances [26]. Strong cervical cancer screening adherence predictors for women of all income are having a regular source of care and a physician recommending screening $[27,28,29]$. These services may be difficult to obtain for women from lower socioeconomic backgrounds. In addition women from lower socioeconomic backgrounds have low levels of health literacy and in general low educational levels which may explain low adherence levels $[30,31]$ even though free health insurance is available.

This was evident in the Patras study, since women with high school or university level education were 3 to 4 times more likely to have had a Pap test compared to women with some or no school education, a finding confirmed by other studies $[16,22,23,26]$. Furthermore, women of low education were less likely to repeat screening after 3 years compared to women of higher education. Finally, employed women were 2 times more likely to have had a Pap test compared to women who did not work, another finding confirmed by the literature [32].

Screening behavior was not influenced by health care coverage, BMI, house ownership or alcohol consumption in the present study. The lack of a significantly positive association between screening behavior and health care coverage may be due to the high prevalence of women who had health care coverage (95.1\%).

The study also shows a positive correlation between number of smoking pack-years and Pap testing. Women who had over 5pack-years were about 3 times more likely to receive a Pap test than those who didn't. This may be explained as a consequence of an increased level of awareness of heavy smokers due to their hazardous habit. On the other hand, less heavy smokers $(<1$ pack-year) seem to have less regular Pap tests compared to non-smokers, a finding also observed in several other studies.[16, 33-35]. However, the number of heavy smokers in the sample was low $(5.3 \%)$ therefore more research needs to be conducted in order to establish an association with smoking.

Although studies have consistently shown an inverse relationship between obesity and screening behavior (decreased cervical cancer screening with increasing BMI) [36-38], this study did not detect a statistically significant relationship between Pap test screening and BMI.

Most EU countries have had population based Pap screening test programs since the early 60s. Finland, Luxemburg and Sweden were the first to establish these programs followed by other MS [14]. Most programs were financially supported by government resources. Unfortunately no such programs exist in Greece up until now.

The National Action Plan for Cancer which has been in effect since 2008 includes a number of measures for the prevention of cancer including cervical cancer. There are plans to implement organized population based cervical cancer screening on a national basis and according to the European Guidelines for Quality Assurance for Cervical Cancer screening. Due to the existing financial crisis there is no further information on when these plans will be put into effect.

Since 2006 when the study was conducted HPV vaccination was introduced to the Greek National Immunization schedule in 2007. The age of the target population is 12 to 15 years old and the recommended catch-up age is 16 to 26 years. Vaccination is offered free of charge for females aged 12-26 according to specific criteria and it is not compulsory, but given on demand. The costs of the vaccine are fully reimbursed by the social insurance funds.

Latest developments show that a program that combines cervical cancer screening using the Pap test, HPV vaccination and molecular testing for HPV type will drastically improve cervical cancer detection and treatment 
[39].

The main limitation of the present study is that the data were collected 7 years ago and prior to the financial crisis. However, the 2006 data for screening among women in Patras are valuable for future comparisons especially in terms of measuring the impact of the financial crisis on health seeking behaviors such as screening for cervical cancer or HPV vaccination.

Follow up study should investigate the uptake of HPV vaccinations among the population in Patras as this will provide new insights to the cervical cancer screening profile of the city as well as to help create or improve policy recommendations.

\section{Conclusions}

It is important that findings from this study are widely disseminated in particular among local stakeholders. Given the financial crisis that has affected Greece since 2009 it is expected that problems for people belonging to low socioeconomic groups will intensify and that health seeking behaviors such as screening for cervical cancer among this group would have worsened. Local authorities should utilize existing and low cost mechanisms to implement awareness raising activities for the local community. Such mechanisms include local TV and radio stations as well as local health care services. Nevertheless, the best method to reduce cervical cancer is the implementation of a population based organized screening program according to the EU guidelines which would also facilitate the collection of consistent data for statistical monitoring. This would enable optimal examination, application and comparison of new test methodologies such as HPV-testing and would also facilitate evaluation of the program. In the long term this is the best way to reduce health costs related to the treatment of cervical cancer and the best argument for policy makers in the context of the current financial crisis.

\section{Acknowledgements}

We would like to thank all the women participating in this study.

\section{REFERENCES}

[1] Globocan 2008 (IARC) Section of Cancer Information [cited 2012 Dec 5]. Available from: http://globo can.iarc.fr/factsheets/populations/factsheet.asp?uno $=900$

[2] Jemal A, Bray F, Center MM, Ferlay J, Ward E, Forman D. Global cancer statistics. CA Cancer J Clin 2011;61:69-90

[3] Arbyn M., Raifu AO, Weiderpass E , Bray F, Anttila A. Trends of cervical cancer mortality in the member states of the European Union. Eur J Cancer 2009;45:2640-2648.
[4] Arbyn M, Antoine J, Valerianova Z. Trends in cervical cancer incidence and mortality in Bulgaria, Estonia, Latvia, Lithuania and Romania. Tumori 2010;96:517-523.

[5] IARC. Cervix Cancer Screening. IARC Handbooks of Cancer Prevention. Lyon: IARC Press 2005;10:1-302.

[6] Nygard JF, Skare GB, Thoresen SO. The cervical cancer screening programme in Norway, 1992-2000: changes in Pap smear coverage and incidence of cervical cancer. J Med Screen 2002;9:86-91

[7] Council of the European Union. Council Recommendation of 2 December 2003 on Cancer Screening (2003/878/EC). Off J Eur Union 2003;878:34-38.

[8] Riza E, Kyriakogianni-Psaropoulou P, Koumantakis E, Symiakaki H, Garas I, Linos A. Cervical cancer screening in Greece. Eur J Cancer 2000;36(17):2227-32.

[9] Dimitrakaki C, Boulamatsis D, Mariolis A, Kontodimopoulos $\mathrm{N}$, Niakas D, Tountas Y. Use of cancer screening services in Greece and associated social factors: results from the nation-wide Hellas Health I survey. Eur J Cancer Prev 2009;18(3):248-57.

[10] Panagoulopoulou E, Alegakis A, Abu Mourad T, Sanidas E, Makrigiannakis A, Philalithis A. The role of general practitioners in promoting cervical cancer screening: a field survey in a rural area of Crete, Greece. Eur J Cancer Prev. 2010;19(2):160-6

[11] Ministry of Health, 2008.National Action Plan for Cancer. [cited 2011 Dec 5] Available from: http://www.ygeianet.gov.gr/HealthMapUploads/Files/karkin os_teliko.pdf

[12] Simou E, Maniadakis N, Pallis A, Foundoulakis E, Kourlaba G. Factors associated with the use of pap smear testing in Greece. J Womens Health 2010;19(8):1577-85.

[13] WHO/ICO Information Centre on HPV and Cervical Cancer (HPV Information Centre). Human Papillomavirus and Related Cancers in Greece. Summary Report 2010 [cited 2011 Feb 15]. Available URL: http//www.who.int/hpvcentre.

[14] Linos A, Riza E. Comparisons of cervical cancer screening programs in the European Union. Eur $\mathrm{J}$ Cancer 2000;36(17):2260-5.

[15] Mandelblatt JS, Gold K, O'Malley AS, Taylor K, Cagney K, Hopkins JS,et al. Breast and cervix cancer screening among multiethnic women: role of age, health, and source of care. Prev Med 1999;28(4):418-25

[16] Selvin E, Brett KM. Breast and cervical cancer screening: sociodemographic predictors among White, Black, and Hispanic women. Am J Public Health 2003;93(4):618-23

[17] Adams EK, Breen N, Joski PJ. Impact of the National Breast and Cervical Cancer Early Detection Program on mammography and Pap test utilization among white, Hispanic, and African American women: 1996-2000. Cancer 2007;109:348-58.

[18] Coughlin SS, Leadbetter S, Richards T, Sabatino SA. Contextual analysis of breast and cervical cancer screening and factors associated with health care access among United States women, 2002. Soc Sci Med 2008;66(2):260-75

[19] Coughlin SS, King J, Richards TB, Ekwueme DU. Cervical 
cancer screening among women in metropolitan areas of the United States by individual-level and area-based measures of socioeconomic status, 2000 to 2002. Cancer Epidemiol Biomarkers Prev 2006;15(11):2154-9.

[20] Coughlin SS, Uhler RJ. Breast and cervical cancer screening practices among Hispanic women in the United States and Puerto Rico, 1998-1999. Prev Med 2002;34(2):242-51.

[21] Welch C, Miller CW, James NT. Sociodemographic and health-related determinants of breast and cervical cancer screening behavior, 2005. J Obstet Gynecol Neonatal Nurs 2008;37(1):51-7.

[22] Wilcox LS, Mosher WD. Factors associated with obtaining health screening among women of reproductive age. Public Health Rep 1993;108:76-86.

[23] Katz SJ, Hofer TP. Socioeconomic disparities in preventive care persist despite universal coverage. Breast and cervical cancer screening in Ontario and the United States. JAMA 1994;272:530-534.

[24] Curry RH, Moen JB, Morris SJ, Scheivelhud L. Community directed cancerscreening program. Cancer Pract 1994;2:256-263.

[25] Kaiser N, Coker C, Argueta C, Riggs M, Betancourt H. (2006). Disparities in cervical cancer screening. In $\mathrm{H}$. Betancourt (Chair), Investigating culture and health disparities: The case of cancer screening. Symposium conducted at the meeting of the Society for the Psychological Study of Social Issues, Long Beach, CA

[26] World Health Organization. WHO Guidance Note. Comprehhensive cervical cancer prevention and control: a healthier future for girls and women. WHO, 2013.

[27] O'Malley AS., Forrest CB., \& Mandelblatt J. Adherence of Low-income Women to Cancer Screening Recommendations. The Roles of Primary Care, Health Insurance, and HMOs. J Gen Intern Med. 2002 February; 17(2): 144-154.

[28] Bindman AB, Grunbach K, Osmond D, Vranizan K, Stewart A. Primary care and receipt of preventive services. J Gen Intern Med. 1996;11:260-76.

[29] Flocke SA, Stange KC, Zyzanski SJ. The association of attributes of primary care with the delivery of clinical preventive services. Med Care. 1998;36:AS21-30 .
[30] Harlem Study Team. Mandelblatt J, Traxler M, Lakin P, Kanetsky P, Kao R. Mammography and Papanicolaou smear use by elder poor black women. J Am Geriatr Soc. 1992;40:1001-7.[PubMed]

[31] Lindau ST, Tomori C, Lyons T, Langseth L, Bennett CL, Garcia P. The association of health literacy with cervical cancer prevention knowledge and health behaviors in a multiethnic cohort of women. Am J Obstet Gynecol 2002; 186:938-43.

[32] Grangé G, Malvy D, Lançon F, Gaudin AF, El Hasnaoui A. Factors associated with regular cervical cancer screening. Int J Gynecol Obstet 2008;102(1):28-33

[33] MacLaughlan SD, Lachance JA, Gjelsvik A. Correlation Between Smoking Status and Cervical Cancer Screening: A Cross-Sectional Study. J Low Genit Tract Dis 2011;15(2):114-9.

[34] Rakowski W, Clark MA, Ehrich B. Smoking and Cancer Screening for Women Ages 42-75: Associations in the 1990-1994 National Health Interview Surveys. Prev Med 1999;29:487-95.

[35] Marteau TM, Hankins M, Collins B. Perceptions of risk of cervical cancer and attitudes towards cervical screening: a comparison of smokers and non-smokers. Fam Pract. 2002;19(1):18-22.

[36] Cohen SS, Palmieri RT, Nyante SJ, Koralek DO, Kim S, Bradshaw $\mathrm{P}$,et al. Obesity and screening for breast, cervical and colorectal cancer in women: a review. Cancer 2008;112(9):1892-904.

[37] Maruthur NM, Bolen SD, Brancati FL, Clark JM.The Association of Obesity and Cervical Cancer Screening: A Systematic Review and Meta-analysis. Obesity (Silver Spring). 2009;17(2):375-81.

[38] Amy NK, Aalborg A, Lyons P, Keranen L. Barriers to routine gynecological cancer screening for White and African-American obese women. Int $\mathrm{J}$ Obes $2006 ; 30(1): 147-55$.

[39] Bauch CT., Li M., Chapman G., \& Galvani AP. Adherence to cervical screening in the era of human papillomavirus vaccination: how low is too low? Lancet Infect Dis 2010; 10 : $133-37$ 